\title{
Drivers of Labour Productivity in Flower Farms in Naivasha, Kenya
}

\author{
Jared Isaboke Mose ${ }^{1}$ \\ ${ }^{1}$ Moi University School of Agriculture and Natural Resources, Department of Agricultural Economics and \\ Resource Management, P.O. Box 3900-30100 Eldoret, Kenya \\ Correspondence: Jared Isaboke Mose, Moi University School of Agriculture and Natural Resources, Department \\ of Agricultural Economics and Resource Management, P.O. Box 3900-30100 Eldoret, Kenya. Tel: \\ 254-726-776-990. E-mail: mosejared@yahoo.com
}

\author{
Received: July 24, 2017 Accepted: August 17, 2017 Online Published: October 8, 2017 \\ doi:10.5539/sar.v6n4p117 URL: https://doi.org/10.5539/sar.v6n4p117
}

\begin{abstract}
Although Kenya is the most successful producer and exporter of fresh produce and flowers in sub-Saharan Africa, other countries both in Africa and elsewhere, offer strong competition that could erode export market share in future. Increased labor productivity is crucial for Kenya's competitiveness. This study aimed at examining the key drivers of labour productivity in flower farms in Naivasha, Kenya. Descriptive survey design was employed and stratified proportionate random sampling technique used to select 381 respondents from who data was collected using a questionnaire. A log-linearized Cobb-Douglas model was used examine determinants of labour productivity. The results showed that workers' participation in Labor unions, Information \& Communication Technology and workers' skills acquired through training were the major factors that determined labour productivity by 35.4 percent, 19 percent and 14.7 percent respectively. While worker's wage increase and tools used by a worker influenced labour productivity by 9 percent and 11.4 percent respectively. Worker's level of education and worker's experience also increased labour productivity by 5.1 percent and 4 percent respectively. The study recommends that; the Kenyan government should give special attention to education to produce skilled and innovative workers. Flower Farms should invest more in training of workers to acquire relevant skills, acquisition of appropriate tools; improve ICT infrastructure and support labor union in the flower farms.
\end{abstract}

Keywords: flower farms, labor, productivity, drivers

\section{Introduction}

Kenya is the third largest flower exporter in the global market which is dominated by Netherlands which accounts for about 55 percent of total global exports followed by Colombia 18 percent (Ksoll et al 2009). Flower industry is Kenya's top foreign exchange earner. It employs over 50,000 people directly and supports several hundred thousand indirectly. It contributes to the country's status as a leading African economy and provides a source of income for many Kenyans.

Growing globalization leading to expansion in commodities market and competition has made labour productivity a deciding factor in the competitiveness and survival of firms. High labour productivity translates to reduced labour expenses and capacity of the farm to charge competitive prices for goods produced. Due to the foregoing there has been great interest in determinants of labour productivity and productivity growth in recent literature. Labor productivity typically gives manpower input expressed as labor expense to the amount of output generated (Borcherding and Liou, 1986). Alternatively, labor productivity may be defined as the quantity of output generated by labor (manpower) in a given period (Drewin, 1982).

Productivity is of paramount importance in the flower industry where it makes a major portion of inputs used in flower production. The internal and external environment in the flower subsector is dynamic leading to a constant change in labor productivity. It is imperative that decline in productivity is minimized since substantial cost is reduced if productivity is enhanced and equal amount of work realized using less labor, translating to lower total cost of labor (Thomas, 1991). Research in the past has shown that research and development (R\&D) expenditure of an organization, its level of information technology in the Farm (IT), export intensity, size of firm, training of human resources and education are important drivers of productivity. Educating and training of laborers are normally recognized as human capital in the texts. This study examined the level of education and 
skills acquired through training as independent variables affecting on labour productivity among workers of flower farms. Amassing of human capital largely through raising productivity of labor force leads to higher efficiency in the use of physical capital besides enabling the generation and use of new technologies. Studies by Fisher and Hostland (2002) and Shaw (2002) suggest that increased labor productivity improves the living standards of people. In order to raise labor productivity, it is essential to examine the level of labor productivity, its growth rate and identify the factors influencing it. In literature, three factors are considered as primary causes of labor productivity increase. The first is education usually measured as average years of attending school which contributes in a positive manner to higher labour productivity (Yunhua et al., 2000; Duryea and Pages, 2002 and Razzak and Timmins, 2007). The second cause is health normally measured in terms of life expectancy at birth which has been found to enhance labor productivity growth (Leroex et al., 2003; Hazan, 2006; Knapp, 2007 and Chadha, 2008). The third cause is technological progress measured by the growth rate of total factor productivity which past research found to be positively related to labour productivity growth (Jajri and Ismail, 2009). This paper aimed at examining the key drivers of labour productivity in flower farms in Naivasha, Kenya.

The rest of the paper is organized as follows. Section 2 describes the theoretical framework. Section 3 discusses the study design. Section 4 presents the study findings and discussion and section 5 concludes.

\section{Theoretical Framework}

Labor productivity is a notion used by theoretical economists: Neoclassical, Keynesians or Radical economists. The Marxist theory of labor value informed this study. The Marxian theory of labor value propounded in Marx's masterpiece, Capital (1867) is a major pillar of traditional Marxist economics. The theory's basic assertion is that the value of a good can be objectively measured by the average amount of labour hours required to produce that good. Marx suggested that productivity is the reciprocal of the value of goods. This idea has re-emerged in various Marxist authors, such as Gouverneur (2002), and Valenzuela (1986). David Ricardo originally set forth the idea that both direct and indirect labor are spent in producing each good, presented in input-output analysis, when he referred to incorporated labor and by Karl Marx when he spoke of abstract labor. The Marxist meaning of productivity suggests that a rise in the efficiency in manufacturing of a good has a profound effect on production of many other goods, and may as well affect the entire production system. The Marxist concept of abstract labor emphasizes that: every single good is strictly the result of using a part of social labor and not only of the labor process that immediately appears as its origin. Marx correctly noted that not only does each production process use a multiplicity of inputs, but also because an increase in the efficiency with which a means of consumption is produced enables an increase in consumption of all goods. Higher productivity in the production of means of production leads to a greater consumption of the means of production and of all the commodities employing it.

According to Leibenstein (1957) workers' productivity is assumed to be positively determined by real wage paid. He stressed the relationships among wages, nutrition and health in developing countries. According to him, firms in developing countries get healthier and more productive workers if they pay higher wages. Solow (1979) formulated similar model for developed countries which states that higher wages boosts workers' morale and thus directly improves productivity by raising work effort by workers.

The Labour Turnover Model (Lawler 1981) asserts that workers are expected to be more hesitant to leave employment owing to the greater salary paid by the present employer and the poorer the opportunities in the outside labor market. If firms must endure part of the costs of labor turnover and if exit rates are a decreasing function of wages paid, firms have motivation to pay high salaries to reduce high labor turnover.

According to Sociological Model (Akerlof \& Yallen 1992), labourers' effort in work primarily hinges on the degree to which they feel they are being treated justly by their companies. The alleged fairness of the salary may affect worker productivity if performance levels are related to worker motivation and feelings of allegiance to the firm. The Functional Theory (Pylee \& Simon 1996) suggests that a person who is cheerful and in good physical shape is a better, more productive worker. Here, well-being is used as a means to attain, protect and improve the efficiency and productivity of labor. Approaches to any answers, particularly those involving the employees and the management should involve negotiation and an accepting of one another's perspective. This will guarantee submission by both parties to agreements that have been reached.

\subsection{Model Estimation}

The model that was used in the paper was similar to Artige and Nicolini (2006) that was designed to examine Labor productivity in Europe. Moreover, a model of Papadogonas and Voulgaris (2005) that was used to examine the factors influencing labour productivity in Greece businesses was also employed. Therefore the study used a modified log-linear Cobb-Douglas production function to estimate the determinants of labour productivity 
in the flower farms in Naivasha.

$$
Y_{i}=\alpha_{0} K_{i}^{\alpha_{1}} L_{i}^{\alpha_{2}}
$$

Where $L_{i}$, is labour input, $K_{i}$ is capital input and $Y_{i}$ is output. $\alpha_{1}$, and $\alpha_{2}$ are the returns to scale of capital and labour respectively while $\alpha_{0}$ is a constant.

By dividing equation (1) by $L$ the resulting equation estimates labour efficiency of the farm.

$$
\left(\frac{Y_{i}}{L_{i}}\right)=\alpha_{0}\left(\frac{K_{i}}{L_{i}}\right)^{\alpha_{1}}\left(L_{i}\right)^{\alpha_{1+\alpha_{2-1}}}
$$

By introducing other determinants of labor productivity apart from labour and capital which include education of the worker, experience of the worker, worker's skills acquired through training, Labor unions for workers and wages of workers the resulting equation is:

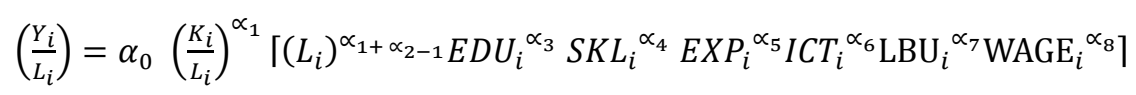

From equation 3 above, EDU is the level of education of a worker in the farm, SKL, stands for skills acquired through training by a worker, EXP, is the experience of workers and LBU is worker's Labour Union. WAGE is worker's wage increase, $\frac{K_{i}}{L_{i}}$ is taken to proxy tools used by a worker and ICT represent farm's technology in the flower farms.

Considering the log -linear form of (3) above we get;

$$
\ln \left(\frac{Y_{i}}{L_{i}}\right)=\ln \alpha_{0}+\propto_{1} \ln \left(\frac{K_{i}}{L_{i}}\right)+\left(\propto_{1}+\propto_{2}-1\right) \ln L_{i}+\propto_{3} \ln E D U_{i}+\propto_{4} \ln S K L_{i}+\propto_{5} \ln E X P_{i}+\propto_{6} \ln L B U_{i}+\propto_{7} \ln W A G E_{i}+u_{i}(4)
$$

From equation 4 above, $\left(\propto_{1}+\propto_{2}-1\right) \ln L_{i}=0$ since $\propto_{1}, \propto_{2}$ are the returns to scale of capital and labour respectively, where $\propto_{1}+\propto_{2}=1$.The model estimation of the study finally takes the form of (5) below after simplification.

$$
\ln \left(\frac{Y_{i}}{L_{i}}\right)=\ln \alpha_{0}+\propto_{1} \ln \left(\frac{K_{i}}{L_{i}}\right)+\propto_{2} \ln E D_{i}+\propto_{3} \ln S K L_{i}+\propto_{4} \ln I C T_{i}+\propto_{5} \ln E X P_{i}+\propto_{6} \ln L B U_{i}+\propto_{7} \ln W A G E+u_{i}
$$

Where;

$\ln \left(\frac{Y_{i}}{L_{i}}\right):$ Represent the logarithm of worker's Labour Productivity.

$\ln \left(\frac{K_{i}}{L_{i}}\right)$ : Represent the logarithm of worker's tools in the farm proxy to capital.

$\ln E D_{i}$ : Represent the logarithm of worker's level of Education.

$\operatorname{lnSKL} L_{i}$ : Represent the logarithm of skilled acquired through training by a Worker.

$\operatorname{lnICT}_{i}$ : Represent the logarithm of Technology in the farm.

$\ln W A G E_{i}$ : Represent the logarithm of worker's wage increase.

$\ln E X P_{i}$ : Represent the logarithm of worker's experience proxy to number of years worked.

$\ln L B U_{i}$ : Represent the logarithm of the proportion of unionized workers to the labour force of the farm.

$u_{i}:$ is the error term of the model.

$\alpha_{0}, \propto_{1} \ldots \ldots \propto_{7}$ are the estimation parameters of the regression model.

This model was estimated as multiple linear regression using cross-sectional survey data from the farm workers, using Statistical Package for Social Sciences (SPSS) software version 20.0. The statistical data were drawn out from the farm level using questionnaires. In this study experience of worker was taken proxy to the number of working years in the flower farm by a worker, fixed capital proxy to tools used by a worker in the flower farms.

\section{Study Design}

This study was carried out in the flower farms in Naivasha Sub-County, Kenya. Flower growing is currently intensely carried out around Lake Naivasha, which is to the north-west of the capital city of Kenya, Nairobi and 
south-west of Naivasha town. Naivasha has a farm area of $970 \mathrm{Km}^{2}$. The Division has areas of $365.6 \mathrm{~km}^{2}$ devoted to growing of flower which is done on 38 farms.

The study adopted descriptive survey research design. It was also used to explain and validate the study findings on the determinants of labour productivity among workers in flower farms in Naivasha, Kenya. The study targeted all cut flower laborers in Naivasha, Kenya. These farms are categorized as large, medium and small farms according to their sizes. Large farms were considered to be above 70 hectares, medium farms $22-69$ hectares and small below 22 hectares (KHCR, 2012). For this study, stratified sampling technique was adopted in which the study population was first subdivided into three strata according to size namely: Large scale farms, Medium scale farms and Small scale farms. Proportionate sampling was used to decide the proportion of total population of laborers in each stratum. Thereafter, simple random sampling was also employed within the strata in order to select the respondents who participated in the study. The sample size of 381 respondents was arrived at by using Krejcie and Morgan formula and a questionnaire was used to collect data. A pilot study of 30 flower farm laborers from Bulbs flower farm in Gilgil was carried out to examine the extent to which the questionnaire yielded the same observations in independent measurements of the same empirical phenomenon. This study used primary farm-level data from Naivasha flower farm laborers. Kolmogorov-Smirnov normality test, Glejser test for heteroscedasticity, Durbin Watson statistic and linearity test were conducted for data stability. Data was analyzed using the Statistical Package for Social Sciences (SPSS) software version 20. Multiple regression analysis using ordinary least squares (OLS) technique was performed to determine coefficients of determinants of labour productivity.

\section{Results and Discussion}

The study model was estimated and fitted the results are shown in table 1 below.

Table 1. Determinants of Labor productivity in Naivasha Sub-County

\begin{tabular}{|c|c|c|c|c|c|}
\hline \multirow[t]{2}{*}{ Model } & \multicolumn{2}{|c|}{ Un-standardized Coefficients } & \multirow{2}{*}{$\frac{\text { Standardized Coefficients }}{\text { Beta }}$} & \multirow[t]{2}{*}{$\mathbf{t}$} & \multirow[t]{2}{*}{ Sig. } \\
\hline & $\mathbf{B}$ & Std. Error & & & \\
\hline (Constant) & .213 & .035 & & 6.130 & .000 \\
\hline Experience & .040 & .014 & .070 & 2.817 & .005 \\
\hline Education & .051 & .019 & .066 & 2.715 & .007 \\
\hline Tools & .117 & .019 & 177 & 6.207 & .000 \\
\hline Skills of workers & .147 & .031 & .168 & 4.797 & .000 \\
\hline Labor unions & .354 & .033 & .385 & 10.676 & .000 \\
\hline Wage increase & .091 & .024 & .112 & 3.774 & .000 \\
\hline Technology & .190 & .027 & .218 & 6.913 & .000 \\
\hline $\mathrm{R}$ & & & & & 0.880 \\
\hline R Square & & & & & 0.789 \\
\hline Adjusted R Square & & & & & 0.785 \\
\hline Std. Error of the $\mathrm{E}$ & nate & & & & 0.139 \\
\hline
\end{tabular}

Source: Author, 2016

The results of the study show that schooling positively and significantly affects labor productivity and for every additional level of education attained by farm workers in the flower sector, labor productivity increases by $5.1 \%$. The study results on education agree with other studies such as Black et al. (1996) who found that education level had a positive and significant effect on productivity. Studies by Turcotte and Rennison (2004) examining Canadian firms got similar findings. Education sets a platform for acquisition of new knowledge and relevant skills through training. It is a critical tool in appropriate interpretation of farm instructions and aid in decision making process. It improves the handling and use of technology in the farm, understanding of labor laws and leads to efficiency and effective productivity in the flower farms. A flower farm becomes highly productive as the percentage of workers who are educated increases because such laborers optimally carry out tasks that need learning and serious thinking such as operating cooling and chemical plants in flower farms. It can therefore be argued that, education increases worker's productivity through the following: Educated workers have high efficiency that increases flower production in the flower sector; Educated flower farm workers lead to increase in final productivity of capital that facilitates economic growth in the community; Educated flower farm workers enhance technical changes in their production which suspend the law of diminishing returns and leads to increased levels of per worker productivity; and Educated flower farm workers on equal terms, are able to 
come out with innovations with the optimal allocation of scarcely available resources that increases their labor productivity in the flowers farms.

Experience of workers was examined in the study and the number of working years a worker had worked in the flower farm was used as a proxy for this variable. In this study worker's experience was positive and significant and explained 4 percent variation on worker's productivity in the farms. The results of the study are consistent with the notion of learning-by-doing as $1 \%$ increase in working years increases per worker productivity by $4 \%$ in the flower farms. It can be argued that employees become more industrious by mastering farm's specific competencies for cutting flowers. Aggrey et al. (2010) found that there was no significant association of experience with labour productivity.

The study results show that the tools used by workers explain 11.7 percent variation in worker's productivity. This means that as the tools increase and become readily available for the workers, per worker productivity increases by 11.7 percent. Thus tools have a positive and significant impact on per worker productivity in flower farms. There is therefore need to increase the number of tools for cutting flowers as well as facilitating training of workers to acquire relevant skills for handling and use of tools to maximize per worker flower production in the flower farms. Tools make work easier; enhance effectiveness and efficiency in flower production by workers. Access to readily available tools by workers increases their efficiency and reduces drudgery as well as improving labor productivity in the farms.

The results also suggest the existence of a positive and significant relation between training/skills and labor productivity. It is can be interpreted thus; for every training session a farm worker participates in, labor productivity increases by 14.7 percent. Other studies in the review of literature have also found skills of workers to have a significant effect on labor productivity. Aggrey et al. (2010) in their investigation of African manufacturing firms found out that training and hence skills acquired through training; positively and significantly affects labor productivity. Other studies by Bartel (1994), Hozler et al. (1993), Huselid (1995), Almeida and Carneiro (2008) arrived at the same conclusion. Today, skilled workforce is recognized as one of the most important sources of economic growth; therefore, training farm workers will accelerate not only economic growth but also the living standards of the workforce through increased productivity.

It is also evident from the results of the study that, workers' participation in labor unions had a positive and significant effect on labour productivity in the flower farms with a slope of 0.354 . It can therefore be stated that for every labour union a worker joins in the flower farms, per worker productivity increases by 35.4 percent. This was interpreted that, as labour unions negotiated for pay increase and improved working conditions for workers in the flower farms, employers demanded and rewarded direct worker productivity in terms of number of pieces of flower cut in a day. Individual workers are therefore exposed and are bound to meet their daily threshold set by management as well as enjoying protection from other forms of oppression by employers. Labor unions in the flower farms protect and lobby for improved work conditions for the workers. Labor unions agitate for wage increase thus improve workers morale. Unionization increases cooperation and comes with positive changes in procedural arrangement and coordination in the flower farms that is offset by improved labor productivity. Studies by Aggrey et al. (2010) assert that workers participation in a trade union was significantly associated with labour productivity in Sub-Saharan African manufacturing firms.

Wage as a variable in the study showed a positive and significant (9.1\%) influence on worker productivity. A wage increase boosts workers' morale as well as improving their living standards in the flower farms. There is therefore need to increase workers' wages in order to increase their motivation and thus their productivity. The results of this study agree with studies by Huang et al. (1998) on Chinese industrial sector who also found that there was a positive and significant effect of workers wage increase on their productivity.

Technology in this study shows a positive relation with 19 percent effect on labor productivity. This significant influence shows how important Technology is in the production of flowers by workers in the flower farms. Through Technology, flower farmers in even the most remote locations can easily and readily access vital information on market prices, pests and diseases as well as input prices. Social media in the flower farms also provide a platform for rural communities to contribute to policy-making in the flower farms. Technology will facilitate expansion of business process for instance marketing flower farm products as well as transmission of information between administrators and workers which in turn improves labor productivity. Technology creates a smooth communication process from laborers through management to global flower market. Quality preservation and storage, packaging, marketing and transportation of flowers and flower products are key determinants of success in the flower sector that can only be achieved through technology. Brynjolfsson et al. (1995) showed that accumulation physical capital in the arena of technology enhances labor productivity. 
Furthermore Papadogonas et al. (2005) while investigating Greek industrial firms concluded that increase in capital equipment concentration led to labour productivity enhancement. Access to information and communication technology devices such as computers, phone lines as well as internet connectivity in flower farms is one of the primary determinants of labor productivity.

\section{Conclusion}

The main conclusion of this study is that workers' participation in labor unions, increase in information \& communication technology; enhancement in skills acquired through training; increase in tools used by workers in the flower farms; increase in worker's wage; increase in worker's levels of education; and increase in worker's experience will increase labor productivity. This information isvital in promoting the flower sector and enhancing global competitiveness as Kenya undergoes transition and adjustment in the sector.

\section{References}

Aggrey, N., Luvanda, E., \& Shitundu, J. (2010). Human Capital and Labor Productivity in East African Manufacturing Firms, Current Research Journal of Economic Theory, 2(2), 48-54.

Akerlof, G. A. (1982). Labor Contracts as Partial Gift Exchange, Quarterly Journal of Economics, 97, 54369. https://doi.org/10.2307/1885099

Almeida, R., \& Carneiro, P. (2008). The Return to Firm Investments in Human Capital. Labour Economics, 16(1). 97-106. https://doi.org/10.1016/j.labeco.2008.06.002

Artige. L., \& Nicolini, R. (2006). Labor Productivity in Europe: Evidence from a sample of regions; Creep working paper. HEC-Management school, University of Liege.

Brynjolfsson, E., \& Hitt, L. (1995). Information Technology as a Factor of Production: The Role of Difference among Firms, Economics, Innovation and New Technology, 3, 183-199. https://doi.org/10.1080/10438599500000002

Duryea, S., \& Pages, C. (2002). Human Capital Policies: What They Can and Cannot Do for Productivity and Poverty Reduction in Latin America. Inter-American Development Bank, Research Department Working Paper Series 468. https://doi.org/10.2139/ssrn.1817264

Fisher, T., \& Hostland, D. (2002). The Long View: Labor Productivity, Labor Income and Living Standards in Canada, in: (eds. T. Fisher and D. Hostland) The Review of Economic Performance and Social Progress (2002), Chapter 2. Centre for the Study of Living Standards and The Institute for Research on Public Policy.

Hazan, M. (2006). Longevity and Lifetime Labor Input: Data and Implication. CEPR Discussion Paper No. 5963.

Huang, Tzu-Ling, Arne Hallam, Peter F. Orazem, \& Elizabeth M. Peter (1998), Empirical Tests of Efficiency Wage Models, Economica, 65, 125-43. https://doi.org/10.1111/1468-0335.00117

Jajri, I., \& Ismail, R. (2009). Technical Progress and Labor Productivity in Small and Medium Scale Industry in Malaysia, European Journal of Economics, Finance and Administrative Sciences, 15, 199-208.

KHRC (Kenya Human Rights Commission) (2012). Wilting in Bloom: The Irony of Women Labor Rights in the Cut Flower Sector in Kenya. Nairobi: KHRC.

Knapp, D. (2007). The Influence of Health on Labor Productivity: An Analysis of European Conscription Data. A Senior Honor Thesis, Department of Economics, Ohio State University.

Krejcie, R. V., \& Morgan, D. W. (1970).Determining Sample Size for Research Activities. Educational and Psychological Measurement. 607-610. https://doi.org/10.1177/001316447003000308

Ksoll, C., Macchiavello, R., \& Morjaria, A. (2011). The Effect of Ethnic Violence on an Export Oriented Industry. Working Paper No. 287. Department of Economics, Bureau for Research and Economic Analysis of Development, Duke University, Durham, NC.

Lawler, E. (1981). Pay and Organizational Development: Adison -Wesley readings.

Leroux, J., Rizzo, J., \& Sickles, R. (2003). Health, Mental Health and Labor Productivity: The Role of Self-Reporting Bias, Department of Economics, Rice University Working Paper 2004-09.

Papadogonas, Theodore \& Fotini Voulgaris (2005). Labor Productivity Growth in Greek Manufacturing Firms. Operational Research, 5(3), 459-472. https://doi.org/10.1007/BF02941131

Pylee, M., \& Simion, G. (1996). Industrial relations and personel management: Vikas publishing house, Pvt L.t.d, 
New Delhi p-78

Razzak, W., \& Timmins, J. (2007). Education and Labor Productivity in New Zealand. Munich Personal RePEc Achieve Paper No. 1880.

Romer, P. M. (1990). Endogenous Technological Change. Journal of Political Economy, 98(5), S71-101. https://doi.org/10.1086/261725

Saari, S. (2006). Productivity: Theory and Measurement in Business. Finland: European Productivity Conference.

Turcotte, Julie \& Lori Whewell Rennison (2004). Productivity and Wages: Measuring the Effect of Human Capital and Technology Use from Linked Employer-Employee Data, Department of Finance Working Paper 2004-01.

Yunhua, L., Soon Beng, C., \& WenZhi, L. (2000). Education, Experience and Productivity of Labor in China's Township and Village Enterprises: The Case of Jiangsu Province. China Economic Review, 9, 47-58. https://doi.org/10.1016/S1043-951X(99)80003-0

\section{Copyrights}

Copyright for this article is retained by the author(s), with first publication rights granted to the journal.

This is an open-access article distributed under the terms and conditions of the Creative Commons Attribution license (http://creativecommons.org/licenses/by/3.0/). 